\title{
Excessive Sensory Stimulation during Development Alters Neural Plasticity and Vulnerability to Cocaine in Mice
}

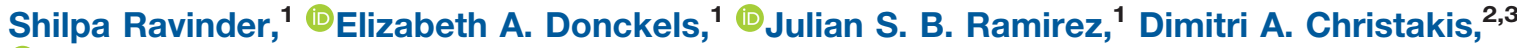 \\ (1) Jan-Marino Ramirez, ${ }^{1,4}$ and Susan M. Ferguson ${ }^{1,5}$
}

\section{DOI:http://dx.doi.org/10.1523/ENEURO.0199-16.2016}

${ }^{1}$ Center for Integrative Brain Research, Seattle Children's Research Institute, Seattle, Washington $98101,{ }^{2}$ Center for Child Health, Behavior and Development, Seattle Children's Research Institute, Seattle, Washington 98121, ${ }^{3}$ Department of Pediatrics, University of Washington, Seattle, Washington 98195, ${ }^{4}$ Department of Neurological Surgery, University of Washington, Seattle, Washington 98195, and ${ }^{5}$ Department of Psychiatry and Behavioral Sciences, University of Washington, Seattle, Washington 98195

\begin{abstract}
Early life experiences affect the formation of neuronal networks, which can have a profound impact on brain function and behavior later in life. Previous work has shown that mice exposed to excessive sensory stimulation during development are hyperactive and novelty seeking, and display impaired cognition compared with controls. In this study, we addressed the issue of whether excessive sensory stimulation during development could alter behaviors related to addiction and underlying circuitry in CD-1 mice. We found that the reinforcing properties of cocaine were significantly enhanced in mice exposed to excessive sensory stimulation. Moreover, although these mice displayed hyperactivity that became more pronounced over time, they showed impaired persistence of cocaine-induced locomotor sensitization. These behavioral effects were associated with alterations in glutamatergic transmission in the nucleus accumbens and amygdala. Together, these findings suggest that excessive sensory stimulation in early life significantly alters drug reward and the neural circuits that regulate addiction and attention deficit hyperactivity. These observations highlight the consequences of early life experiences and may have important implications for children growing up in today's complex technological environment.
\end{abstract}

Key words: amygdala; drug addiction; environment; mice; nucleus accumbens; sensory stimulation

\section{Significance Statement}

Environmental stimulation in the form of enrichment has been shown to be beneficial for brain development and behavior. Although this has been broadly interpreted as stimulating the developing brain is advantageous, recent work demonstrates that sensory stimulation can in fact have negative consequences, particularly if it is non-normative and extensive, and is presented during development. This research adds to existing knowledge on the impact of early life experiences and provides fundamental insights into how environmental factors during development can shape the brain and behavior. At a point where childhood and adolescence is increasingly dominated by exposure to audiovisual media, we believe our findings build the case for further investigation into the effects of extended exposure to sensory experiences in early life. 


\section{Introduction}

Attention-deficit/hyperactivity disorder (ADHD) and drug addiction are neuropsychiatric diseases with a high comorbidity rate and a strong genetic component (Capusan et al., 2016). However, there remains a large role for environmental factors in the etiology of these diseases (McCrory and Mayes, 2015). It is widely recognized that early life experiences shape neural function, which can have lasting impacts on behavior and result in vulnerability to the development of these diseases. For example, childhood stress during periods of critical development increases the propensity to impulsive choice, ADHD, and drug use/abuse later in life, whereas positive life experiences, such as good family and peer relations, can be protective against the development of ADHD and decrease the likelihood of drug use (Jessor and Jessor, 1980; Kodjo and Klein, 2002; Sinha, 2008; Enoch, 2012). Studies in rodent models have found similar effects. Animals exposed to stress early in life show impulsivity, impaired decision-making, greater motivation to seek drugs, and increased rates of drug-induced reinstatement (McEwen, 2003; Rüedi-Bettschen et al., 2006; Andersen and Teicher, 2009). On the other hand, rodents reared in an enriched environment, which provides plenty of complex inanimate and social stimulation, have enhanced decision-making and cognition, decreased motivation to seek drugs, and lower rates of drug-induced reinstatement (Solinas et al., 2010; Takuma et al., 2011).

Although much of the laboratory animal work on environmental risk factors has focused on impoverished versus enriched environments, recent studies in humans have shown that exposure to extensive periods of auditory and visual stimulation during childhood is highly correlated with attentional problems (Christakis et al., 2004; Zimmerman and Christakis, 2007). However, human studies cannot be used to establish a causal relationship between excessive sensory exposure and behavioral consequences. As such, we have only a limited understanding of how increased sensory stimulation alters brain function and behavior, and changes the risk for neuropsychiatric illness. While the introduction of animal models to study the consequences of an enriched environment has led to deep and detailed insights into the underlying cellular mechanisms, we know very little about the conse-

Received July 12, 2016; accepted August 9, 2016; First published August 11, 2016.

The authors declare no competing financial interests.

Author contributions: S.R., J.S.B.R., D.A.C., J.-M.R., and S.M.F. designed research; S.R. and E.D. performed research; S.R., J.-M.R., and S.M.F. analyzed data; J.S.B.R., D.A.C., J.-M.R., and S.M.F. wrote the paper.

This study was funded by the Seattle Children's Research Institute.

Acknowledgments: We thank Tatiana Dashevskiy for assistance in generating cumulative distribution curves.

Correspondence should be addressed to Susan M. Ferguson, Center for Integrative Brain Research, Seattle Children's Research Institute, 1900 9th Avenue, Seattle, WA 98101. E-mail: smfergus@uw.edu.

DOI:http://dx.doi.org/10.1523/ENEURO.0199-16.2016

Copyright (C) 2016 Ravinder et al.

This is an open-access article distributed under the terms of the Creative Commons Attribution 4.0 International, which permits unrestricted use, distribution and reproduction in any medium provided that the original work is properly attributed. quences of excessive sensory stimulation (ESS). Only two recent studies have investigated the effects of repetitive sensory stimulation. One study (Hadas et al., 2016) showed that repetitive olfactory stimulation during development in rats impaired performance in an attention task in the presence of an auditory distractor. Using repetitive auditory and visual stimulation in a mouse model, the second study (Christakis et al., 2012) reported that extended exposure to sensory stimulation during development produces pronounced hyperactivity, impaired cognition, and increased novelty seeking. In the present study, we have used the same mouse model to examine the effects of excessive exposure to sensory stimulation during development on the rewarding and psychomotor activating effects of cocaine, using conditioned place preference and locomotor sensitization, respectively. In addition, we characterized whether this stimulation protocol produces baseline changes in neural activity in two components of the neural circuits thought to contribute to addiction and ADHD, the nucleus accumbens (NAc) and the amygdala.

\section{Materials and Methods}

\section{Experimental animals}

Male CD-1 mice purchased from Charles River Laboratories (RRID:SCR_013551) were used for all experiments. Mice (postweaning) were group housed (three to five per cage) with ad libitum access to food and water under a $12 \mathrm{~h}$ light/dark cycle (light on at 7:00 A.M.) and with a controlled temperature $\left(22 \pm 1^{\circ} \mathrm{C}\right)$. All experiments and animal procedures were performed in accordance with the regulations of the Seattle Children's Research Institute animal care committee, and were conducted in accordance with the National Institutes of Health guidelines.

\section{Excessive sensory stimulation paradigm}

Mice received sensory stimulation in their home cages for 42 consecutive days starting at postnatal day 10 (P10). The stimulation occurred during the dark cycle for $6 \mathrm{~h} / \mathrm{d}$. The dam was stimulated along with the pups from P10 until weaning (P21). Control groups were raised under standard laboratory housing conditions and tested at corresponding times with the sensory stimulation groups. The sensory stimulation setup consisted of two loudspeakers, suspended 2 inches above the top of the cage. Auditory stimulation consisted of audio from television cartoon shows (e.g., Pokemon, Powerpuff girls, Bakugan), which were layered on top of each other, with one pitch shifted (10-20 kHz), and one non-pitch-shifted track in order to better accommodate the higher-frequency hearing range of mice. Sounds were no louder than $70 \mathrm{~dB}$, which is significantly lower than the common auditory stress model. Light-emitting diode (LED) lights (red, green, yellow, and blue) were placed around the cages to provide visual stimulation. A photorhythmic modulator was used to change the frequency of the blinking LED lights in concordance with the sound output from the speakers. 


\section{Behavioral tests}

\section{Conditioned place preference}

The conditioned place preference (CPP) test is a classic pavlovian conditioning procedure used to study the reinforcing effects of unconditioned stimuli (e.g., drugs, food). The CPP test was performed in a three-chamber placepreference box (ENV-3013, Med Associates) using an unbiased, three-phase design (preconditioning, conditioning, and postconditioning). The CPP test was conducted on control and ESS mice from P52 to P56 (preconditioning test, P52; conditioning, P53 to P55; postconditioning test, P56). The apparatus consisted of two large compartments separated by a central neutral compartment. The two lateral compartments differed in floor texture and wall pattern: vertically striped walls and stainless steel grid rods for flooring on one side, and horizontally striped walls and metal mesh flooring on the other; the small central compartment had a smooth floor. During the preconditioning phase, mice were placed in the central compartment and allowed 15 min of free access to all compartments of the CPP box. During the conditioning phase, mice received twice daily (morning and afternoon) conditioning sessions for $3 \mathrm{~d}$. On each conditioning day, mice were confined to one compartment for $15 \mathrm{~min}$ immediately following the administration of saline (morning) or cocaine $(15 \mathrm{mg} / \mathrm{kg}$, i.p.; obtained from the National Institute on Drug Abuse; afternoon). The choice of compartment for saline/cocaine pairing was randomized and counterbalanced across groups. During the postconditioning phase, mice were given 15 min of free access to the CPP apparatus on the day following the final conditioning session. Time spent in the compartments was tracked using Noldus EthoVision XT 8.0. A CPP score was calculated for each mouse as the difference between preconditioning and postconditioning time spent in the drug-paired compartment. A change in preference for the drug-paired compartment serves as an index of the reinforcing effects of cocaine.

\section{Activity assessment and psychomotor sensitization}

Activity levels in mice and the psychomotor activating effects of cocaine were measured using locomotor activity boxes $(8.5 \times 17.5 \times 9$ inches $)$ from San Diego Instruments (SDI) that contained regular ground corncob bedding on the floor. The Photobeam Activity System software (SDI) was used to track total crossovers in a $4 \times$ 8 photobeam configuration, which provided a measure of locomotor activity. To induce psychomotor sensitization, mice received 10 treatment sessions over a 2 week period (induction phase, P52-P65). During each session, mice were habituated to the locomotor chambers for $45 \mathrm{~min}$ followed by an injection of cocaine (15 mg/kg, i.p.) or saline, and locomotor activity was monitored for $60 \mathrm{~min}$. After a 2 week withdrawal period, all mice received an escalating dose challenge of cocaine (challenge phase). During this phase, mice received a 45 min habituation period, followed by sequential injections of saline 10 $\mathrm{mg} / \mathrm{kg}$ and cocaine $20 \mathrm{mg} / \mathrm{kg}$ spaced $60 \mathrm{~min}$ apart. Locomotor activity was monitored for the entire duration of the session, and total crossovers within the 60 min sessions were plotted and used for statistical analysis.

\section{In vitro slice electrophysiology}

Slice electrophysiology experiments were conducted on control and ESS mice at P52-P70. Their brains were quickly removed under deep anesthesia, and 350- $\mu \mathrm{m}$ thick coronal slices containing the NAc shell or the lateral amygdala (LA) and basal amygdala (BA) were prepared. We chose to study these particular subregions as a vast body of literature shows that these brain regions are interconnected and are required for cocaine-related behaviors, and cellular changes in these subregions are thought to underlie the behavioral effects of cocaine administration (Thomas et al., 2001; Fuchs et al., 2002; Kourrich and Thomas, 2009; Stuber et al., 2011; Lee et al., 2013; Hsiang et al., 2014). Slices were transferred to a submerged chamber containing artificial CSF (aCSF; in mM: $124 \mathrm{NaCl}, 2.7 \mathrm{KCl}, 26 \mathrm{NaHCO}$, 0.4 NaH2PO4, 10 glucose, 4 sodium ascorbate, $1.3 \mathrm{MgCl} 2$, and $2 \mathrm{CaCl} 2)$ equilibrated with $95 \% \mathrm{O}_{2} / 5 \% \mathrm{CO}_{2}$ at room temperature. Slices were incubated for at least $1 \mathrm{~h}$ before being transferred to a superfused recording chamber. Excitatory pyramidal neurons in the $\mathrm{BA}$ or medium spiny neurons in the NAc shell were visually identified using a Zeiss Axioskop 2 FS microscope with infrared differential interference contrast. Patch electrodes (3-6 M $\Omega$ ) were pulled from borosilicate glass pipettes on a P-97 Flaming-Brown Micropipette Puller (Sutter Instruments) and filled with the voltage-clamp pipette internal solution [for miniature EPSCs (mEPSCs; in mM): $120 \mathrm{CsOH}, 120$ gluconic acid, 20 CsCl, 10 HEPES, $4 \mathrm{MgATP}$, and $0.3 \mathrm{NaGTP}$, and 10 phosphocreatine, pH 7.3, 300 mOsm; for mIPSCs (in mM): $140 \mathrm{CsCl}, 1010$ HEPES, 10 phosphocreatine, 4 MgATP, and 0.3 NaGTP, pH 7.3, 290 mOsm]. Whole-cell patchclamp recordings were performed using an Axon Multiclamp $700 \mathrm{~B}$ patch-clamp amplifier. All recordings were performed at $30^{\circ} \mathrm{C}$. Neurons were voltage clamped at $-70 \mathrm{mV}$. mEPSCs were isolated by using $75 \mu \mathrm{M}$ picrotoxin and $0.5 \mu \mathrm{M}$ TTX in the aCSF solution, and miniature IPSCs (mIPSCs) were isolated by adding $10 \mu \mathrm{M}$ CNQX, 30 $\mu \mathrm{M}$ D-APV, and $0.5 \mu \mathrm{M}$ TTX in the aCSF solution. Continuous current traces were recorded for a $5 \mathrm{~min}$ period. Series resistance $\left(R_{s}\right)$ was monitored before and after the experiment, and only cells with an $R_{s}$ value $<25 \mathrm{M} \Omega$ were taken for analysis. Data were filtered at $2.1 \mathrm{kHz}$ and digitized at $10 \mathrm{kHz}$. The amplitude and frequency of mEPSCs and mIPSCs were analyzed using the Mini Analysis Program (Synaptosoft). The firing output of BA neurons was measured in the current-clamp mode [internal solution composition (in $\mathrm{mm}$ ): $140 \mathrm{~K}$-gluconate, 10 HEPES, 1 $\mathrm{CaCl}_{2}, 2 \mathrm{MgSO}_{4}, 4 \mathrm{Na}_{2} \mathrm{ATP}, 0.3 \mathrm{Na}_{2} \mathrm{GTP}$, and 10 EGTA], and the membrane potential was adjusted to $-70 \mathrm{mV}$ before the injection of each current pulse. Action potential firing in response to a series of depolarizing current steps was recorded. Saturating current intensities were excluded from the analysis. Some basic properties of BA principal neurons were also measured in the currentclamp mode. The resting membrane potential $\left(V_{\mathrm{m}}\right)$ was measured immediately after achieving whole-cell configuration by bringing the holding current to $0 \mathrm{pA}$. The action potential threshold was estimated by injecting a ramp of current (0-500 pA in $100 \mathrm{~ms})$ and measuring the voltage 
at which the first action potential occurred. The currentvoltage relationship ( $I-V$ curve) was analyzed by measuring the peak voltage response to a series of current steps ranging from -100 to $50 \mathrm{pA}$. The input resistance was calculated as the slope of the $I-V$ curve for each neuron.

\section{Corticosterone measurement}

Plasma corticosterone (CORT) levels in control mice and mice that received sensory stimulation were quantified using an ELISA. Following $42 \mathrm{~d}$ of the sensory stimulation protocol, at age P52, mice were killed and blood samples were collected for CORT measurements. Mice were anesthetized with isoflurane and decapitated to collect trunk blood into lithium heparinized tubes (microcontainer 365971, BD). The blood samples were then centrifuged at $10,500 \mathrm{rpm}$ for $10 \mathrm{~min}$ at $4^{\circ} \mathrm{C}$ to isolate plasma. The supernatant was then collected into Eppendorf tubes and stored at $-80^{\circ} \mathrm{C}$ until further analysis. To quantify CORT levels, the plasma sample were thawed, and ELISA assays were performed by following the manufacturer instructions [catalog \#KO14-H5, Arbor Assays (RRID:SCR_013534)].

\section{Statistical analyses}

Statistical analyses were conducted using either twoway repeated-measures ANOVA with Bonferroni's post hoc analysis (to correct for multiple comparisons), or a one-sample or two-sample $t$ test (without correction) when appropriate and as indicated, using Prism (GraphPad; RRID:SCR_000306). Differences were considered to be statistically significant at $p \leq 0.05$.

\section{Results}

\section{Exposure to excessive sensory stimulation during development enhances CPP to cocaine}

The rewarding effects of cocaine were assessed in controls and mice that received ESS using a CPP procedure; testing was performed in a drug-free state (Fig. 1a). We found that both groups of mice acquired a clear preference for the cocaine-paired chamber (Fig. 1b; CON: $t_{(13)}=3.81, p=0.002$; ESS: $\left.t_{(12)}=6.08, p<0.0001\right)$. However, mice that received sensory stimulation during development had a significantly greater CPP score compared with controls (Fig. $1 b ; t_{(25)}=2.09, p=0.04$ ), suggesting that they had a more robust response to the rewarding properties of cocaine.

\section{Exposure to excessive sensory stimulation during development impairs the persistence of cocaine- induced locomotor sensitization}

In a separate cohort of mice, we assessed locomotor activity and the development of cocaine sensitization in control and ESS mice. As expected from other behavioral tests (Christakis et al., 2012), mice that received sensory stimulation during development were significantly more active than controls on the first day of saline treatment, and this effect was stronger by the last test session [Fig. $1 c$; main effect of stimulation: $F_{(1,14)}=18.02, p=0.0008$; $p<0.05$ (session 1) and $p<0.001$ (session 10) vs control]. Thus, sensory stimulation during development led to hyperactivity that became increasingly more pro- nounced with repeated exposure to the testing environment. Given the differences in locomotor activity in saline groups, the responses of the cocaine groups were normalized to these different baselines (by subtracting the average total crossovers in the corresponding saline group from the total crossovers for each mouse) in order to gain a clearer picture of the impact of developmental sensory stimulation exposure on locomotor sensitization to cocaine. During the induction phase of sensitization, we found that the acute locomotor response to cocaine was decreased in mice that received extended periods of sensory stimulation during development compared with controls, although this effect did not quite reach statistical significance [Fig. 1d, left; main effect of stimulation: $F_{(1,19)}=10.82, p=0.004 ; p=0.1$ (session 1) vs control]. Nonetheless, both groups showed significant increases in locomotor responses following repeated cocaine treatment, suggesting that sensitization had developed in all mice (Fig. 1d, left; main effect of session: $F_{(1,19)}=14.97$, $p=0.001$; no interaction: $\left.F_{(1,19)}=0.71, p=0.41\right)$.

Following a 2 week withdrawal period, all mice underwent a challenge session, which included an injection of saline to test for the development of a conditioned response in mice that had previously received cocaine injections. As expected, control mice showed a conditioned locomotor response to this saline injection; however, mice that were exposed to the sensory stimulation protocol did not (Fig. 1d, left; main effect of pretreatment: $F_{(1,33)}=$ $10.17, p=0.003 ; p=0.009$ vs saline-pretreated control). In addition, both groups of mice that received cocaine treatment during the induction phase showed greater locomotor responses to the challenge doses of cocaine compared with the saline-treated mice. However, the cocaine-treated mice that received the sensory stimulation exposure during development had significantly decreased locomotor responses during the cocaine challenge compared with controls (Fig. $1 d$, right; $10 \mathrm{mg} / \mathrm{kg}$ : main effect of pretreatment: $F_{(1,33)}=$ 36.47, $p<0.0001$; main effect of stimulation: $F_{(1,33)}=5.42$, $p=0.03 ; p=0.007$ vs cocaine-pretreated controls; 20 $\mathrm{mg} / \mathrm{kg}$ : main effect of pretreatment: $F_{(1,33)}=27.57, p<$ $0.0001 ; p=0.05$ vs cocaine-pretreated controls), suggesting that the persistence of sensitization was impaired. Thus, despite the fact that exposure to excessive sensory stimulation during development produces hyperactivity, it also results in blunted locomotor sensitization to cocaine.

\section{Exposure to excessive sensory stimulation is not stressful}

Stress is a well known modulator of the behavioral effects of cocaine (Shaham et al., 2000; Kreibich et al., 2009). Thus, to assess whether the stimulation paradigm results in a stress phenotype, body weights and plasma CORT levels were measured in mice at P53 (i.e., $24 \mathrm{~h}$ following the last stimulation exposure). We found that body weights were the same in mice that were exposed to excessive periods of sensory stimulation during development and in control mice (Fig. $2 a ; t_{(69)}=1.30, p=0.20$ ). In addition, there were no differences in plasma CORT levels between control mice and those that underwent the sensory stimulation protocol (Fig. $2 b ; t_{(18)}=0.93, p=$ 
a

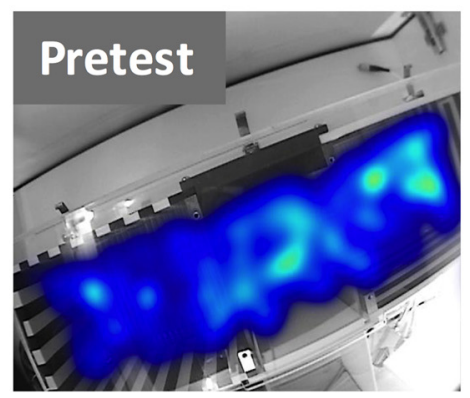

C
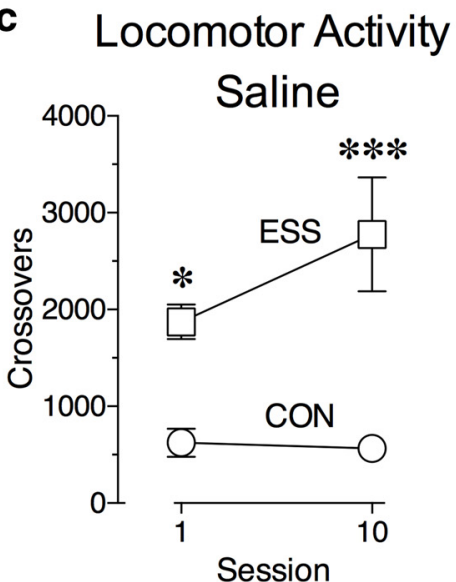
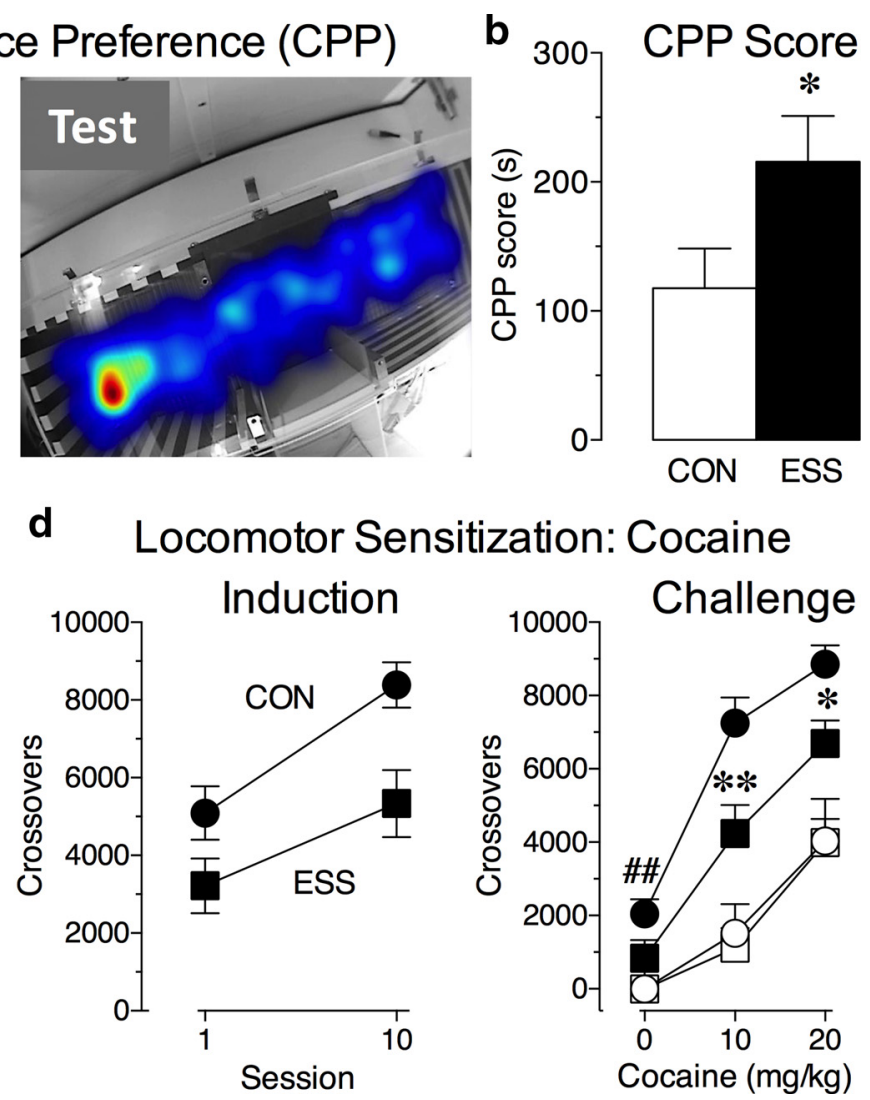

sitization

CON

Figure 1. Exposure to excessive sensory stimulation (ESS) during development alters behavioral responses to cocaine and locomotor activity. a, Representative heat map of time spent in the different compartments of the CPP box during the pretest (left) and on the test (right). $\boldsymbol{b}$, Mice exposed to ESS during development had a significantly greater CPP score compared with control (CON) mice (*p $<0.05$ vs CON; $n=13-14$ /group). c, Locomotor activity following saline administration in CON mice (white circles) and ESS (white squares) mice, as measured by the total number of crossovers. Exposure to ESS during development led to a significant increase in locomotion compared with controls ( $* p<0.05$ vs CON mice in session $1 ; * * * p<0.001$ vs CON mice in session 10; $n=7-9 /$ group). $\boldsymbol{d}$, Left, induction phase, Total number of crossovers made during the 60 min following cocaine injection normalized to baseline responding (i.e., the average total crossovers in the corresponding saline group were subtracted from total crossovers for each mouse) in CON (black circles) and ESS (black squares) mice. Exposure to ESS during development had no effect on the development of locomotor sensitization during cocaine treatment ( $n=10-11$ mice/group). Right, challenge phase, Total number of crossovers made during the 60 min following each dose of a multidose challenge $(0,10$, and $20 \mathrm{mg} / \mathrm{kg}$ cocaine). Responses normalized to the corresponding saline pretreatment group at the $0 \mathrm{mg} / \mathrm{kg}$ challenge. Control mice that received cocaine during the induction phase, but not mice that were exposed to ESS during development, displayed a conditioned locomotor response (\#\#p = 0.009 vs saline-pretreated CON mice). In addition, ESS mice showed a significantly blunted locomotor sensitization to cocaine $(* * p=0.007$ vs cocaine-pretreated CON; $* p=0.05$ vs cocaine-pretreated CON mice in session $10 ; n=7-11$ mice/group). Data represent the mean \pm SEM.

0.37). These observations suggest that the extended exposure to lights and sounds used in the sensory stimulation protocol does not alter baseline stress levels in the mice.

\section{Exposure to excessive sensory stimulation during development increases the frequency of miniature EPSCs in limbic circuits}

To begin to explore neural correlates of the observed behavioral changes, we next examined whether exposure to excessive sensory stimulation produces a fundamental shift in neuronal activity by measuring mEPSCs in the shell region of the NAc, as well as the LA and BA nuclei of the amygdala. In the NAc (Fig. 3), we found that, while mEPSC amplitude was not different between groups (Fig. $\left.3 e ; t_{(18)}=0.57, p=0.58\right)$, there was a significant increase in the frequency of mEPSCs in the mice that received sensory stimulation during development compared with control mice (Fig. $3 d ; t_{(18)}=4.67, p=0.0002$ ).

Similarly, we found a significant increase in the frequency $\left(t_{(18)}=2.35, p=0.03\right)$, but not in the amplitude $\left(t_{(18)}=0.58, p=0.57\right)$, of mEPSCs in the BA of young mice that had received sensory stimulation compared with control mice (Fig. 4a). In contrast, we found no difference in the frequency $\left(t_{(18)}=0.68, p=0.51\right)$ or amplitude $\left(t_{(18)}=1.45, p=0.16\right)$ of mEPSCs in the LA (Fig. 4b). This observation was specific to excitatory currents in the BA as we observed no difference in either the frequency $\left(t_{(18)}=0.33, p=0.74\right)$ or the amplitude $\left(t_{(18)}=\right.$ $0.89, p=0.39$ ) of mIPSCs in BA principal neurons 
a

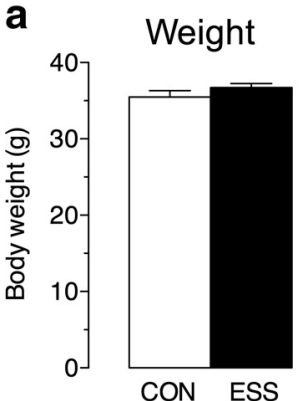

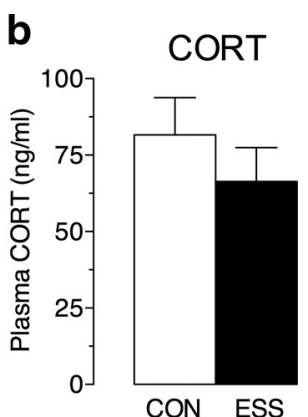

Figure 2. Exposure to excessive sensory stimulation (ESS) does not affect measures of a stress response. a, Exposure to ESS during development does not alter body weight at P53 (i.e., the day after the end of ESS exposure) compared with control (CON) mice ( $n=32-39$ mice/group). $\boldsymbol{b}$, Plasma CORT levels at P53. Exposure to ESS during development does not affect baseline plasma CORT levels compared with CON mice ( $n=10$ mice/ group). Data represent the mean \pm SEM.

(Fig. 4c). Interestingly, we found that the increase in mEPSC frequency $\left(t_{(17.05)}=2.05, p=0.05\right)$ in BA neurons persisted even 2 months after the end of stimulation, suggesting that these cellular changes are long lasting (Fig. 4d).

In order to test the functional consequence of enhanced mEPSC frequency on BA neurons, we measured the firing output of BA principal neurons. Neurons were current clamped with the membrane potential maintained at -70 $\mathrm{mV}$, and action potential firing in response to somatic injections of increasing steps of depolarizing currents was recorded (Fig. 5a). We found that while there was a significant increase in firing rates with current injection across both groups, there was no significant difference in firing rates between cells from slices of mice that received excessive sensory stimulation during development and control mice (Fig. 5b; main effect of current: $F_{(10,110)}=$ 24.38, $p<0.0001$; no main effect of stimulation: $F_{(1,11)}=$ $0.54, p=0.48)$. Other basic properties measured in the current-clamp mode, namely, resting membrane potential, action potential threshold, the $I-V$ curve, and input resistance, were not different between $B A$ neurons in control and ESS mice (Fig. $5 c-f$ ). These findings indicate that excessive periods of sensory stimulation lead to a specific increase in the frequency of mEPSCs in the BA and the NAc.

\section{Discussion}

Early-life experiences have critical influences on the development of neural circuits, and on susceptibility to drug use and addiction (Andersen and Teicher, 2009; Solinas et al., 2010). Understanding these influences is very important as early life experiences not only drive adaptation, but, under certain conditions, can be a major source of maladaptation. Enriched environments in rodents are known to be procognitive, to decrease addiction vulnerability, and to enhance brain function, whereas impoverished environments have the opposite effects (Fabel and Kempermann, 2008; Kempermann et al., 2010; Volkers and Scherder, 2011). However, unlike the positive effects of an enriched environment, it has recently been shown that exposure to extended periods of sensory stimulation during development in mice produces ADHD-like symptoms, including hyperactivity, impaired cognition, increased novelty seeking, and increased distractability (Christakis et al., 2012; Hadas et al., 2016). Here we found that exposure to excessive sensory stimulation also enhances the rewarding effects of cocaine while blunting its psychomotoractivating effects. This is a significant finding, given the high comorbidity of ADHD and addiction (Zernicke et al., 2010; Jupp and Dalley, 2014). In addition, this result is consistent with work examining psychostimulant-induced locomotor activity and sensitization using other models of ADHD that express a hyperactive phenotype, such as the dopamine transporter knock-out mouse and the spontaneously hypertensive rat (Sagvolden et al., 2005). However, it is possible that the enhanced CPP observed in the stimulated mice was due to alterations in learning and memory, and this possibility will be explored in future studies.

In addition to these behavioral alterations, this excessive stimulation paradigm leads to a lasting enhancement in the frequency of mEPSCs in principal neurons of the amygdala and NAc, regions that are critical components of the neuronal circuits that regulate cognition, impulsivity, and reward. Although profound and widespread, the neurobiological changes caused by excessive sensory stimulation are very specific. In particular, the baseline increases in mEPSC frequency in the BA and the NAc shell raise the intriguing possibility that excessive sensory experiences during childhood and adolescence lead to a fundamental shift in excitatory drive from sensory inputs to these regions, which in turn could affect the threshold for generating behavioral responses through downstream projections of these regions. Thus, because of an altered set point, children exposed to excessive sensory stimulation may need higher levels of stimulation to elicit a behavioral action, which is reminiscent of children with ADHD. Dissecting the mechanisms underlying these changes, as well as how these alterations in baseline plasticity contribute to the dysregulated behaviors observed in sensory stimulation-induced attentional problems, ADHD, and addiction, warrant future investigation.

The amygdala is an essential component of the circuitry that assigns emotional valence to external stimuli and produces appropriate behavioral responses (Aggleton, 2000; Phelps and LeDoux, 2005). It is also an important part of the brain circuits that regulate learning and memory, anxiety, and addiction (Davis, 1992; Roozendaal et al., 2009; Koob and Volkow, 2010), and aberrant amygdala activity is associated with numerous psychiatric illnesses, including ADHD and addiction (Kilts, 2001; Anand and Shekhar, 2003; King et al., 2003; See et al., 2003). In particular, the BA subregion of the amygdala has been found to play a key role in behaviors related to drug addiction (Baxter and Murray, 2002; Fuchs et al., 2002; Tye and Deisseroth, 2012; Heldt et al., 2014; Hsiang et al., 2014). Similarly, the NAc is also a critical component of these circuits, and changes in NAc activity are also associated with ADHD and addiction (Genro et al., 2010; Koob and Volkow, 2010). Specifically, the integration of dopa- 
a

CON

NAc mEPSC

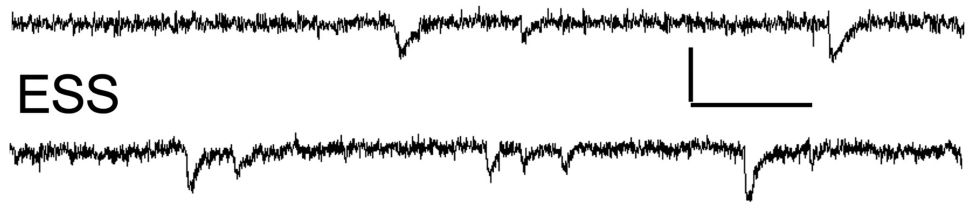

b

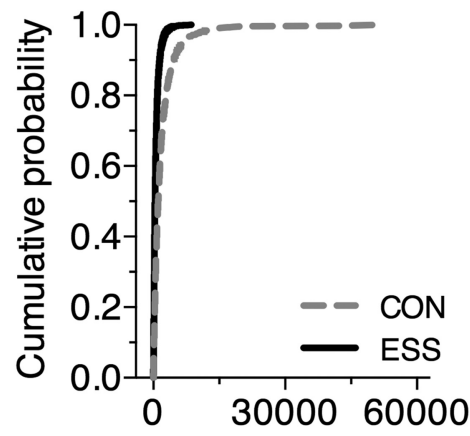

Inter-event interval (ms)

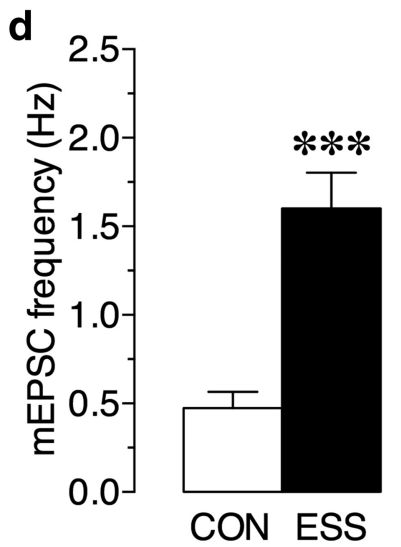

C

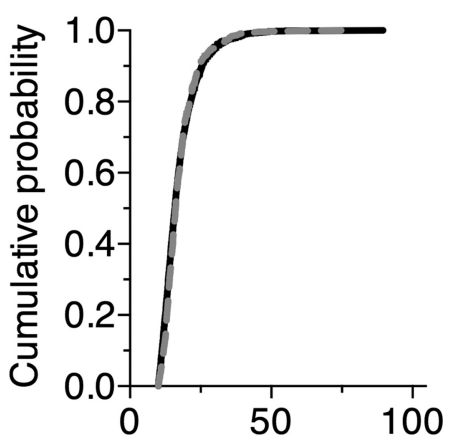

Amplitude (pA)

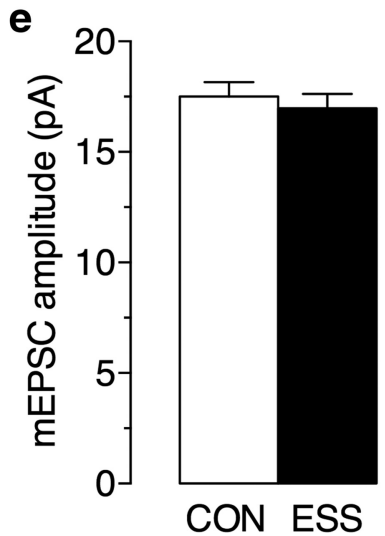

Figure 3. Excessive sensory stimulation (ESS) ESS enhances excitatory tone in the nucleus accumbens (NAc) shell. a, Representative mEPSC traces from NAc shell neurons in slices from control (CON) and ESS mice. $\boldsymbol{b}, \boldsymbol{c}$, Cumulative probability distribution for interevent interval (b) and amplitude (c) of mEPSCs in NAc shell neurons. $\boldsymbol{d}$, e, Exposure to ESS during development significantly increased the frequency ( $* * * p=0.0002 ; n=9-11$ cells/group; $N=3-4$ mice/group), but not the amplitude of mEPSCs in the NAc shell compared with CON mice. Calibration: $20 \mathrm{pA}$ (vertical axis), $50 \mathrm{~ms}$ (horizontal axis). Data represent the mean $\pm \mathrm{SEM}$.

minergic reinforcement signals with glutamatergic signals (from the amygdala, hippocampus, medial prefrontal cortex, and thalamus) that encode information about environmental stimuli leads to plasticity in the NAc that is thought to underlie motivation, reward, and drug-taking and drug-seeking behaviors (Yager et al., 2015). Further, the shell region of the NAc is particularly important for mediating both the rewarding and psychomotor-activating effects of cocaine (Pontieri et al., 1994, 1995; Caine et al., 1995; Pierce and Kalivas, 1995; McKinzie et al., 1999; Parkinson et al., 1999). Given that the BA and NAc are interconnected and can influence circuit function and plasticity, it is likely that the electrophysiological changes that occur in these brain regions following excessive sensory stimulation are contributing to the altered behavioral responses to cocaine (Stuber et al., 2011; Britt et al., 2012; MacAskill et al., 2014).

The sensory stimulation paradigm used in the present set of experiments does not appear to be inherently stressful to mice. The audio stimulation in this model $(70$ $\mathrm{dB})$ is well below the levels typically used in acoustic stress models (100-115 dB). Moreover, stress leads to an increase in anxiety-like behavior (Conrad et al., 1999; Vyas and Chattarji, 2004), while a previous report (Christakis et al., 2012) has found that young mice receiving excessive periods of sensory stimulation show a decrease in anxiety-like behavior. Stress can also affect body weight gain (Vyas et al., 2002; Gao et al., 2011); however, we found no difference in body weights between controls and mice exposed to sensory stimulation (Fig. 3a). In 
a

CON
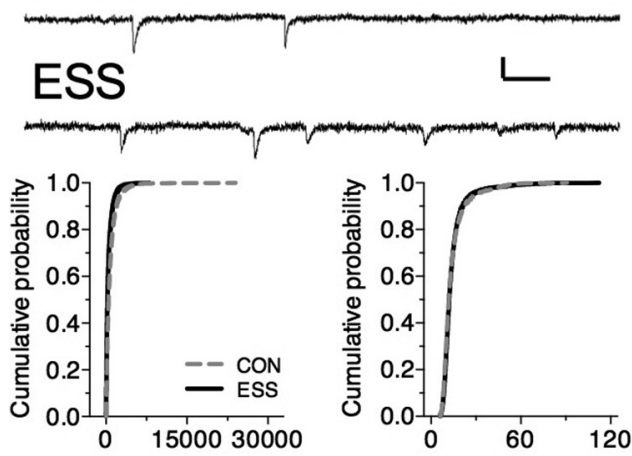

Inter-event interval (ms)
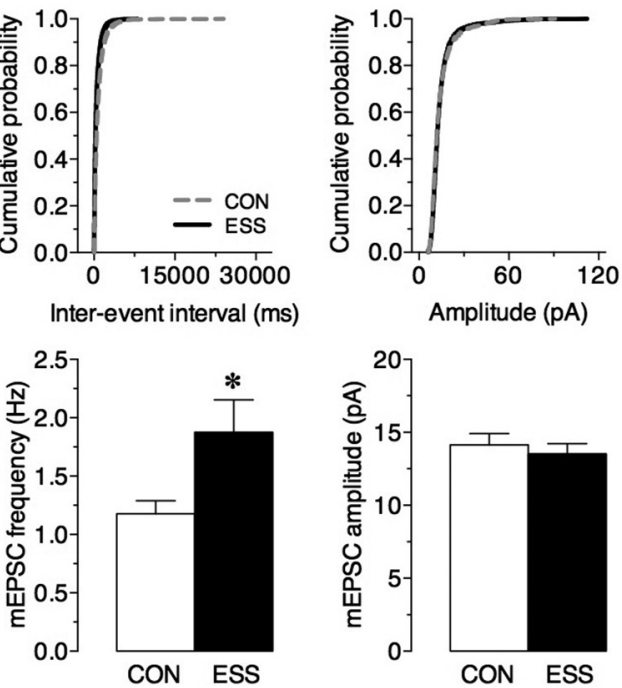

C

CON

BA mIPSC
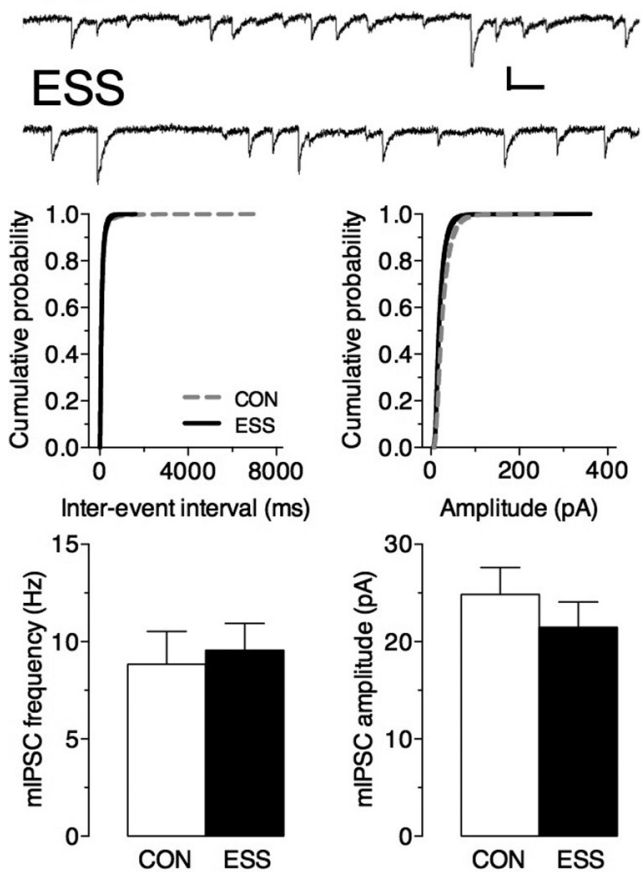

\section{b LA mEPSC}

CON
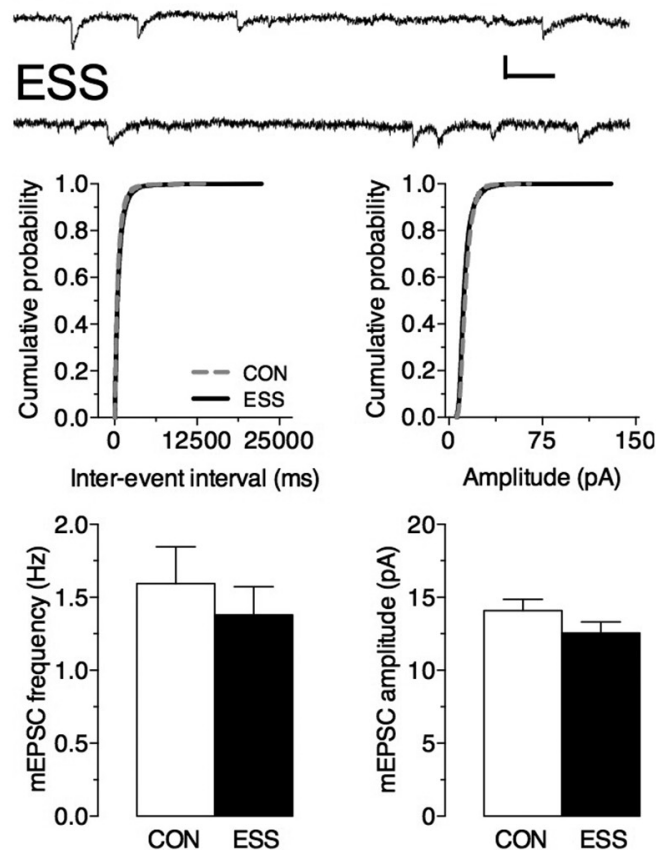

\section{d BA mEPSC: persistence CON}
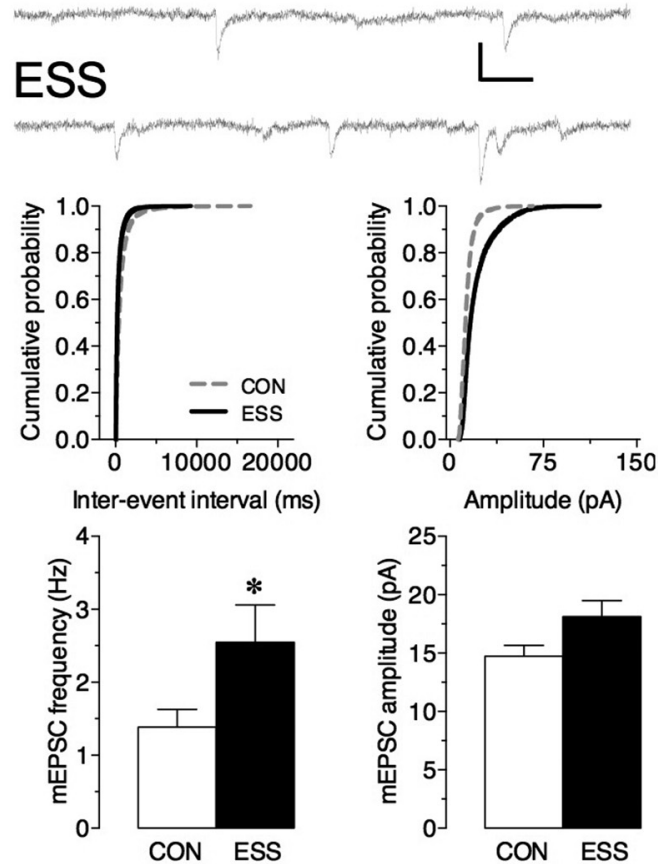

Figure 4. Excessive sensory stimulation (ESS) during development enhances excitatory tone in the basal amygdala (BA). $\boldsymbol{a}$, $\boldsymbol{b}$, Top, Representative mEPSC traces from BA (a) and lateral amygdala (LA) (b) principal neurons in slices from ESS and control (CON) mice. Bottom, Exposure to ESS during development significantly increased the frequency of mEPSCs in the BA $(a$, left: $* p=0.03 ; n=16-17$ cells/group; $N=4-9$ mice/group) but not in the LA (b, left: $n=10$ cells/group; $N=3-4$ mice/group) compared with CON mice. There was no effect of this manipulation during development on the amplitude of mEPSCs in the BA (a, right) or in the LA (b, right). Middle, Cumulative probability distribution for interevent interval (left) and amplitude (right) of mEPSCs in BA (a, center) and LA (b, center) neurons. c, Top, Representative mIPSC traces from BA principal neurons in slices from ESS and CON mice. Bottom, Exposure to ESS during development had no effect on the frequency (left) or the amplitude (right) of mIPSCs in the BA compared to that for CON mice 
continued

( $n=8-10$ cells/group; $N=3-4$ mice/group). Middle, Cumulative probability distribution for the interevent interval (left) and amplitude (right) of mIPSCs in BA neurons. $\boldsymbol{d}$, Top, Representative mEPSC traces from BA principal neurons in slices from adult ESS and CON mice 2 months after the end of the stimulation protocol. Bottom, The mEPSC frequency (d, left: $* p=0.05 ; n=11-13$ cells/group; $N=3-4$ mice/group) but not amplitude (right) was significantly increased 2 months following the end of ESS. Middle, Cumulative probability distribution for the interevent interval (left) and amplitude (right) of mEPSCs in BA neurons 2 months following the end of ESS. Calibration (b-e): 20 pA (vertical axis), 50 ms (horizontal axis). Data represent the mean \pm SEM.

addition, repeated exposure to a stressor normally triggers a hypothalamic-pituitary-adrenal axis response, leading to alterations in baseline plasma CORT levels (Odio and Brodish, 1989); yet, we found that baseline plasma CORT levels in mice that underwent the sensory stimulation protocol were comparable to those in controls (Fig. 3b). Thus, there is no indication that the neurobiological and behavioral effects reported here are caused by stress, experienced directly or indirectly via maternal stress.

Understanding the impact of excessive exposure to sensory stimulation is highly relevant to today's society.
Although animal models do not use the type of stimuli that rodents typically encounter under natural circumstances and cannot fully mimic the human experience, they have nonetheless contributed to a deep mechanistic understanding of the effects of environmental enrichment. Yet we have only very limited mechanistic insights into the consequences of exposure to sensory hyperstimulation. Here we show that in the developing brain that excessive exposure to auditory and visual stimulation alters behavioral susceptibility to cocaine and changes baseline neuronal activity in associated neural circuits. It is conceivable that abnormally patterned stimulation or even too a
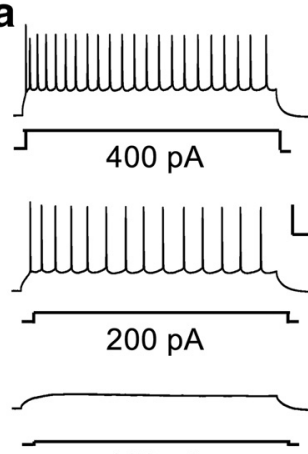

$100 \mathrm{pA}$
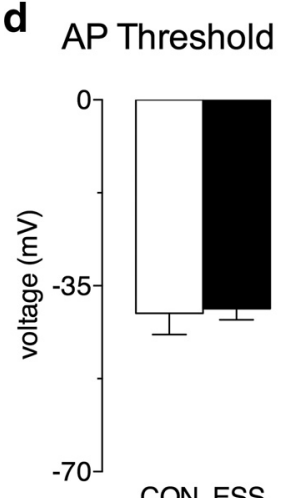

b

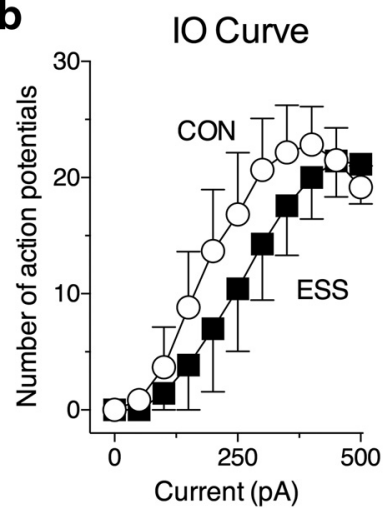

e

IV Curve

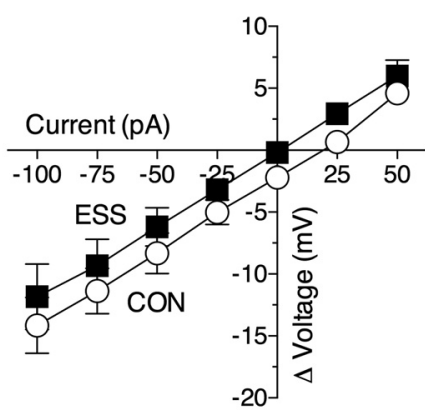

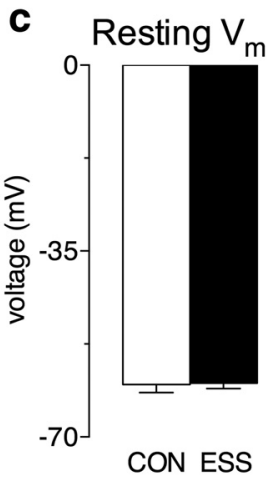

f

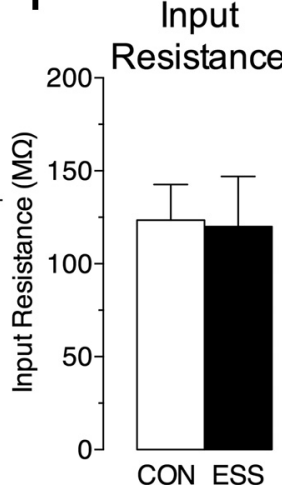

Figure 5. Exposure to excessive sensory stimulation (ESS) does not change action potential firing or basic properties of basal amygdala (BA) principal neurons. a, Representative spike trains evoked by somatic injection of increasing steps of depolarizing currents. $\boldsymbol{b}$, Input-output (I-O) curve (number of action potentials vs current injected) for BA principal neurons in slices from mice exposed to ESS during development (black squares) and control (CON) mice (white circles). There were no differences in the I-O curve between groups ( $n=6-7$ cells/group; $N=3-4$ mice/group). $c-f$, Basic properties of BA principal neurons recorded from control and ESS brain slices. $\boldsymbol{c}$, Resting $V_{\mathrm{m}}$ was not different between BA principal neurons in ESS and CON brain slices ( $n=6-7$ cells/group; $N=3-4$ mice/group). $\boldsymbol{d}$, Action potential threshold (in millivolts) was not different between BA principal neurons in ESS and CON brain slices ( $n=6$ cells/group; $N=3-4$ mice/group). e, The $I-V$ curve was not different between BA principal neurons in ESS and CON brain slices ( $n=5-6$ cells/group; $N=3$ mice/group). $\boldsymbol{f}$, Input resistance was not different between BA principal neurons in ESS and CON brain slices ( $n=5-6$ cells/group; $N=3$ mice/group). Calibration: $40 \mathrm{mV}$ (vertical axis), $100 \mathrm{~ms}$ (horizontal axis). Error bars indicate the mean \pm SEM. 
much sensory stimulation may contribute to the rise in ADHD diagnoses that have started occurring in the past decade, which could in turn influence addiction rates. Interestingly, our research findings along with previous studies on sensory stimulation in rodents are reminiscent of clinical observations in children exposed to extensive television viewing and resemble the three core clinical dimensions of ADHD (inattentiveness, impulsivity, and hyperactivity). In addition, stimulants such as Ritalin normalize the hyperactivity associated with ADHD, and, consistent with this, we found that cocaine-induced locomotor sensitization was blunted in mice that received extended periods of sensory stimulation. Finally, children with ADHD have an increased risk for the development of drug abuse and addiction (Harstad and Levy, 2014), and we found that mice that received sensory stimulation displayed an increase in the rewarding effects of cocaine, indicating an enhanced vulnerability to drugs of abuse. Thus, the excessive sensory stimulation paradigm provides a highly relevant model to understand how environments that contain excessive and ill-patterned stimuli influence behavioral outcomes, change neuroplasticity, and influence the propensity to the development of neuropsychiatric disorders, such as ADHD and addiction.

\section{References}

Aggleton JP (2000) The amygdala: a functional analysis. New York: Oxford UP.[TQ1][TQ2]

Anand A, Shekhar A (2003) Brain imaging studies in mood and anxiety disorders: special emphasis on the amygdala. Ann N Y Acad Sci 985:370-388. Medline

Andersen SL, Teicher MH (2009) Desperately driven and no brakes: developmental stress exposure and subsequent risk for substance abuse. Neurosci Biobehav Rev 33:516-524. CrossRef Medline

Baxter MG, Murray EA (2002) The amygdala and reward. Nat Rev Neurosci 3:563-573. CrossRef Medline

Britt JP, Benaliouad F, McDevitt RA, Stuber GD, Wise RA, Bonci A (2012) Synaptic and behavioral profile of multiple glutamatergic inputs to the nucleus accumbens. Neuron 76:790-803. CrossRef Medline

Caine SB, Heinrichs SC, Coffin VL, Koob GF (1995) Effects of the dopamine D-1 antagonist SCH 23390 microinjected into the accumbens, amygdala or striatum on cocaine self-administration in the rat. Brain Res 692:47-56. Medline

Capusan AJ, Bendtsen P, Marteinsdottir I, Larsson H (2016) Comorbidity of adult ADHD and its subtypes with substance use disorder in a large population-based epidemiological study. J Atten Disord.

Christakis DA, Zimmerman FJ, DiGiuseppe DL, McCarty CA (2004) Early television exposure and subsequent attentional problems in children. Pediatrics 113:708-713. Medline

Christakis DA, Ramirez JS, Ramirez JM (2012) Overstimulation of newborn mice leads to behavioral differences and deficits in cognitive performance. Sci Rep 2:546. CrossRef Medline

Conrad CD, LeDoux JE, Magariños AM, McEwen BS (1999) Repeated restraint stress facilitates fear conditioning independently of causing hippocampal CA3 dendritic atrophy. Behav Neurosci 113:902-913. Medline

Davis M (1992) The role of the amygdala in fear and anxiety. Annu Rev Neurosci 15:353-375. CrossRef Medline

Enoch MA (2012) The influence of gene-environment interactions on the development of alcoholism and drug dependence. Curr Psychiatry Rep 14:150-158. CrossRef Medline

Fabel K, Kempermann G (2008) Physical activity and the regulation of neurogenesis in the adult and aging brain. Neuromolecular Med 10:59-66. CrossRef Medline
Fuchs RA, Weber SM, Rice HJ, Neisewander JL (2002) Effects of excitotoxic lesions of the basolateral amygdala on cocaineseeking behavior and cocaine conditioned place preference in rats. Brain Res 929:15-25. Medline

Gao P, Ishige A, Murakami Y, Nakata H, Oka J, Munakata K, Yamamoto M, Nishimura K, Watanabe K (2011) Maternal stress affects postnatal growth and the pituitary expression of prolactin in mouse offspring. J Neurosci Res 89:329-340. CrossRef Medline

Genro JP, Kieling C, Rohde LA, Hutz MH (2010) Attention-deficit/ hyperactivity disorder and the dopaminergic hypotheses. Expert Rev Neurother 10:587-601. CrossRef Medline

Hadas I, Gal R, Bokovza L, Meiran N, Feifel D, Zangen A (2016) Exposure to salient, dynamic sensory stimuli during development increases distractibility in adulthood. Sci Rep 6:21129. CrossRef Medline

Harstad E, Levy S (2014) Attention-deficit/hyperactivity disorder and substance abuse. Pediatrics 134:e293-e301. CrossRef Medline

Heldt SA, Zimmermann K, Parker K, Gaval M, Weinshenker D, Ressler KJ (2014) BDNF deletion or TrkB impairment in amygdala inhibits both appetitive and aversive learning. J Neurosci 34:24442450. CrossRef Medline

Hsiang HL, Epp JR, van den Oever MC, Yan C, Rashid AJ, Insel N, Ye L, Niibori Y, Deisseroth K, Frankland PW, Josselyn SA (2014) Manipulating a "cocaine engram" in mice. J Neurosci 34:1411514127. CrossRef Medline

Jessor R, Jessor S (1980) A social-psychological framework for studying drug use. NIDA Res Monogr 30:102-109.

Jupp B, Dalley JW (2014) Convergent pharmacological mechanisms in impulsivity and addiction: insights from rodent models. $\mathrm{Br} \mathrm{J}$ Pharmacol 171:4729-4766. CrossRef Medline

Kempermann G, Fabel K, Ehninger D, Babu H, Leal-Galicia P, Garthe A, Wolf SA (2010) Why and how physical activity promotes experience-induced brain plasticity. Front Neurosci 4:189. CrossRef Medline

Kilts CD (2001) Imaging the roles of the amygdala in drug addiction. Psychopharmacol Bull 35:84-94. Medline

King JA, Tenney J, Rossi V, Colamussi L, Burdick S (2003) Neural substrates underlying impulsivity. Ann N Y Acad Sci 1008:160169. Medline

Kodjo CM, Klein JD (2002) Prevention and risk of adolescent substance abuse. The role of adolescents, families, and communities. Pediatr Clin North Am 49:257-268. Medline

Koob GF, Volkow ND (2010) Neurocircuitry of addiction. Neuropsychopharmacology 35:217-238. CrossRef Medline

Kourrich S, Thomas MJ (2009) Similar neurons, opposite adaptations: psychostimulant experience differentially alters firing properties in accumbens core versus shell. J Neurosci 29:1227512283. CrossRef

Kreibich AS, Briand L, Cleck JN, Ecke L, Rice KC, Blendy JA (2009) Stress-induced potentiation of cocaine reward: a role for CRF R1 and CREB. Neuropsychopharmacology 34:2609-2617. CrossRef Medline

Lee BR, Ma YY, Huang YH, Wang X, Otaka M, Ishikawa M, Neumann PA, Graziane NM, Brown TE, Suska A, Guo C, Lobo MK, Sesack SR, Wolf ME, Nestler EJ, Shaham Y, Schlüter OM, Dong Y (2013) Maturation of silent synapses in amygdala-accumbens projection contributes to incubation of cocaine craving. Nat Neurosci 16: 1644-1651. CrossRef Medline

MacAskill AF, Cassel JM, Carter AG (2014) Cocaine exposure reorganizes cell type- and input-specific connectivity in the nucleus accumbens. Nat Neurosci 17:1198-1207. CrossRef Medline

McCrory EJ, Mayes L (2015) Understanding addiction as a developmental disorder: an argument for a developmentally informed multilevel approach. Curr Addict Rep 2:326-330. CrossRef Medline

McEwen BS (2003) Early life influences on life-long patterns of behavior and health. Ment Retard Dev Disabil Res Rev 9:149-154. CrossRef Medline

McKinzie DL, Rodd-Henricks ZA, Dagon CT, Murphy JM, McBride WJ (1999) Cocaine is self-administered into the shell region of the 
nucleus accumbens in Wistar rats. Ann N Y Acad Sci 877:788791. Medline

Odio M, Brodish A (1989) Age-related adaptation of pituitaryadrenocortical responses to stress. Neuroendocrinology 49:382388. Medline

Parkinson JA, Olmstead MC, Burns LH, Robbins TW, Everitt BJ (1999) Dissociation in effects of lesions of the nucleus accumbens core and shell on appetitive pavlovian approach behavior and the potentiation of conditioned reinforcement and locomotor activity by d-amphetamine. J Neurosci 19:2401-2411.

Phelps EA, LeDoux JE (2005) Contributions of the amygdala to emotion processing: from animal models to human behavior. Neuron 48:175-187. CrossRef Medline

Pierce RC, Kalivas PW (1995) Amphetamine produces sensitized increases in locomotion and extracellular dopamine preferentially in the nucleus accumbens shell of rats administered repeated cocaine. J Pharmacol Exp Ther 275:1019-1029. Medline

Pontieri FE, Colangelo V, La Riccia M, Pozzilli C, Passarelli F, Orzi F (1994) Psychostimulant drugs increase glucose utilization in the shell of the rat nucleus accumbens. Neuroreport 5:2561-2564. Medline

Pontieri FE, Tanda G, Di Chiara G (1995) Intravenous cocaine, morphine, and amphetamine preferentially increase extracellular dopamine in the "shell" as compared with the "core" of the rat nucleus accumbens. Proc Natl Acad Sci U S A 92:12304-12308. Medline

Roozendaal B, McEwen BS, Chattarji S (2009) Stress, memory and the amygdala. Nat Rev Neurosci 10:423-433. CrossRef Medline

Rüedi-Bettschen D, Zhang W, Russig H, Ferger B, Weston A, Pedersen EM, Feldon J, Pryce CR (2006) Early deprivation leads to altered behavioural, autonomic and endocrine responses to environmental challenge in adult Fischer rats. Eur J Neurosci 24:28792893. CrossRef Medline

Sagvolden T, Russell VA, Aase H, Johansen EB, Farshbaf M (2005) Rodent models of attention-deficit/hyperactivity disorder. Biol Psychiatry 57:1239-1247. CrossRef Medline

See RE, Fuchs RA, Ledford CC, McLaughlin J (2003) Drug addiction, relapse, and the amygdala. Ann N Y Acad Sci 985:294-307. Medline

Shaham Y, Erb S, Stewart J (2000) Stress-induced relapse to heroin and cocaine seeking in rats: a review. Brain Res Brain Res Rev 33:13-33. Medline
Sinha R (2008) Chronic stress, drug use, and vulnerability to addiction. Ann N Y Acad Sci 1141:105-130. CrossRef Medline

Solinas M, Thiriet N, Chauvet C, Jaber M (2010) Prevention and treatment of drug addiction by environmental enrichment. Prog Neurobiol 92:572-592. CrossRef Medline

Stuber GD, Sparta DR, Stamatakis AM, van Leeuwen WA, Hardjoprajitno JE, Cho S, Tye KM, Kempadoo KA, Zhang F, Deisseroth K, Bonci A (2011) Excitatory transmission from the amygdala to nucleus accumbens facilitates reward seeking. Nature 475:377380. CrossRef Medline

Takuma K, Ago Y, Matsuda T (2011) Preventive effects of an enriched environment on rodent psychiatric disorder models. J Pharmacol Sci 117:71-76. Medline

Thomas MJ, Beurrier C, Bonci A, Malenka RC (2001) Long-term depression in the nucleus accumbens: a neural correlate of behavioral sensitization to cocaine. Nat Neurosci 4:1217-1223. CrossRef Medline

Tye KM, Deisseroth K (2012) Optogenetic investigation of neural circuits underlying brain disease in animal models. Nat Rev Neurosci 13:251-266. CrossRef Medline

Volkers KM, Scherder EJ (2011) Impoverished environment, cognition, aging and dementia. Rev Neurosci 22:259-266. CrossRef Medline

Vyas A, Chattarji S (2004) Modulation of different states of anxietylike behavior by chronic stress. Behav Neurosci 118:1450-1454. CrossRef Medline

Vyas A, Mitra R, Shankaranarayana Rao BS, Chattarji S (2002) Chronic stress induces contrasting patterns of dendritic remodeling in hippocampal and amygdaloid neurons. J Neurosci 22:68106818. Medline Medline

Yager LM, Garcia AF, Wunsch AM, Ferguson SM (2015) The ins and outs of the striatum: role in drug addiction. Neuroscience 301: 529-541. CrossRef Medline

Zernicke KA, Cantrell H, Finn PR, Lucas J (2010) The association between earlier age of first drink, disinhibited personality, and externalizing psychopathology in young adults. Addict Behav 35: 414-418. CrossRef Medline

Zimmerman FJ, Christakis DA (2007) Associations between content types of early media exposure and subsequent attentional problems. Pediatrics 120:986-992. CrossRef Medline 